\title{
Cable Connection Scheme Optimization for Offshore Wind Farm Considering Wake
} Effect

Hou, Peng; Yang, Guangya; Hu, Weihao; Chen, Cong; Soltani, Mohsen; Chen, Zhe

Published in:

Proceedings of IEEE CEC 2018

Publication date:

2018

Document Version

Peer reviewed version

Link back to DTU Orbit

Citation (APA):

Hou, P., Yang, G., Hu, W., Chen, C., Soltani, M., \& Chen, Z. (2018). Cable Connection Scheme Optimization for Offshore Wind Farm Considering Wake Effect. In Proceedings of IEEE CEC 2018 (pp. 654-661). IEEE.

\section{General rights}

Copyright and moral rights for the publications made accessible in the public portal are retained by the authors and/or other copyright owners and it is a condition of accessing publications that users recognise and abide by the legal requirements associated with these rights.

- Users may download and print one copy of any publication from the public portal for the purpose of private study or research.

- You may not further distribute the material or use it for any profit-making activity or commercial gain

- You may freely distribute the URL identifying the publication in the public portal 


\section{Cable Connection Scheme Optimization for Offshore Wind Farm Considering Wake Effect}

\author{
Peng Hou, Guangya Yang \\ Center for Electric Power and Energy \\ Technical University of Denmark \\ Lyngby, Denmark
}

\begin{abstract}
In order to reduce the levelised cost of energy (LCOE) of the offshore wind farm, many optimization works should be done to reduce the investment and increase the energy production. As one of the main expenses, the electrical system can take up more than $15 \%$ of the total investment while cable costs take a large proportion. In order to make a cost-effective wind farm, the cable connection layout should be optimized. This paper proposes a novel way for offshore wind farm cable connection layout design. The LCOE, which concerns three aspects: electrical power losses, power captured by wind turbines (WT) and investment, is selected to set up the objective function. Since all the optimization variables are integers, a heuristic algorithm, integer particle swarm optimization algorithm (IPSO), is adopted to find a near optimal solution. To improve the performance of the IPSO, an adaptive method for parameter control is used to help to find a better solution. Comparisons are made with results obtained by the Norwegian center for offshore wind energy (NORCOWE) reference wind farm and the presented method. From the simulation, it can be noticed that the presented approach can help to find a cable connection scheme which can reduce the $L C O E$ by $1.75 \%$.
\end{abstract}

Keywords-LCOE; cable connection layout; IPSO; NORCOWE

\section{NOMENCLATURE}

\begin{tabular}{|c|c|}
\hline$C_{t}$ & trust coefficient \\
\hline$C_{p}$ & power coefficient \\
\hline$V_{0}[\mathrm{~m} / \mathrm{s}]$ & incoming wind speed \\
\hline$V_{x}[\mathrm{~m} / \mathrm{s}]$ & $\begin{array}{l}\text { wind speed in the wake at a distance } \mathrm{x} \text { along the wind } \\
\text { direction }\end{array}$ \\
\hline$V_{n, m}[\mathrm{~m} / \mathrm{s}]$ & wind speed reached the wind blade at row $\mathrm{n}$, column $\mathrm{m}$ \\
\hline$R_{0}[\mathrm{~m}]$ & WT's rotor radius \\
\hline$S_{\text {eff }}\left[\mathrm{m}^{2}\right]$ & effective wake region \\
\hline$S_{0}\left[\mathrm{~m}^{2}\right]$ & wind blade swept area \\
\hline$V_{d e f, i j}[\mathrm{~m} / \mathrm{s}]$ & the wind speed deficit for WT at row $i$, column $j$ \\
\hline$k_{d}$ & decay constant \\
\hline$P_{m, m n}[\mathrm{MW}]$ & $\begin{array}{c}\text { power extracted from the wind by WT at row } \mathrm{m} \text {, column } \\
n\end{array}$ \\
\hline$N_{\text {row }}$ & the quantity of WTs in a row \\
\hline$N_{c o l}$ & the quantity of WTs in a column \\
\hline$N_{\text {life }}$ & lifetime of wind farm \\
\hline$N_{w}$ & number of wind turbines \\
\hline$P_{\text {loss }, i}[\mathrm{MW}]$ & power losses along cable $\mathrm{i}$ \\
\hline$I_{i}[\mathrm{kA}]$ & current in cable i \\
\hline$R_{\text {res, },}[\mathrm{ohm} / \mathrm{m}]$ & resistance of cable $\mathrm{i}$ \\
\hline $\begin{array}{c}\rho_{\text {res }, i} \\
{\left[\mathrm{ohm} * \mathrm{~m} / \mathrm{mm}^{2}\right]}\end{array}$ & resistivity of selected cable i \\
\hline$l_{\text {res }, i}[\mathrm{~m}]$ & length of cable i \\
\hline
\end{tabular}

\author{
Weihao Hu, Cong Chen, Mohsen Soltani, Zhe Chen \\ Department of Energy Technology \\ Aalborg University \\ Aalborg, Denmark
}

\begin{tabular}{|c|c|}
\hline$S_{r e s, i}\left[\mathrm{~m}^{2}\right]$ & sectional area of cable $\mathrm{i}$ \\
\hline$N$ & $\begin{array}{l}\text { the total quantity of cables that connect wind turbines in } \\
\text { a wind farm }\end{array}$ \\
\hline$P_{t o l, t}[\mathrm{MW}]$ & total power production during interval $\mathrm{t}$ \\
\hline$P_{\text {tol, loss }, t}[\mathrm{MW}]$ & total power losses during interval $\mathrm{t}$ \\
\hline$T_{E}$ & duration interval for energy yields calculation \\
\hline$T_{t}[\mathrm{~h}]$ & duration when the wind farm generating power of $P_{t o l, t}$ \\
\hline$E_{\text {tol,av }}[\mathrm{MWh}]$ & mean energy yields in one year \\
\hline$t$ [hour] & energy yields calculation time \\
\hline$C_{i}[\mathrm{MDKK} / \mathrm{km}]$ & $i^{\text {th }}$ cable's unit cost \\
\hline$A_{1} A_{2} A_{3}$ & the coefficient of cable cost model \\
\hline$I_{i, \text { rated }}[\mathrm{A}]$ & $i^{\text {th }}$ cable's rated current \\
\hline$U_{i, \text { rated }}[\mathrm{V}]$ & $i^{\text {th }}$ cable's rated voltage \\
\hline$H_{i}[\mathrm{~km}]$ & $i^{\text {th }}$ cable's length \\
\hline$Q_{i}$ & the quantity of cable $\mathrm{i}$ \\
\hline$x_{i}$ & selected WT's sequence \\
\hline$C_{a l}$ & capital investment \\
\hline$C_{o g}[\mathrm{Dkk}]$ & the present value of capital cost \\
\hline$N_{y}$ & economic lifetime, 20 years \\
\hline$r$ & discount ratio, 0.02 \\
\hline$w$ & inertia weight \\
\hline$l_{l} l_{2}$ & learning factors \\
\hline$r_{1} r_{2}$ & stochastic variables in the range of $[0,1]$ \\
\hline$x_{i}^{k} x_{i}^{k+1}[\mathrm{~m}]$ & the position of particle $\mathrm{i}$ at iteration $\mathrm{k}$ and $\mathrm{k}+1$ respectively \\
\hline$v_{i}^{k} v_{i}^{k+1}[\mathrm{~m}]$ & the speed of particle $\mathrm{i}$ at iteration $\mathrm{k}$ and $\mathrm{k}+1$ respectively \\
\hline$l c_{i}^{k}[\mathrm{~m}]$ & the best solution obtained from particle $\mathrm{i}$ at iteration $\mathrm{k}$ \\
\hline$g^{l^{k}}[\mathrm{~m}]$ & the best solution obtained from all particles at iteration $\mathrm{k}$ \\
\hline
\end{tabular}

\section{INTRODUCTION}

With the increasing capacity of offshore wind farms, more and more expensive cables are required to transmit the power generated by each wind turbine (WT) to an onshore substation. On the other side, the technology development in wind power field makes the costs of WTs and foundations cheaper than before which makes the percentage of electrical system investment can reach up to $30 \%$ of overall investment [1]. Hence, the importance of optimizing cable connection scheme is becoming more and more prominent in reducing the $L C O E$ of the wind farm.

The offshore wind farm electrical system optimization research can be categorized into two sorts: discrete optimization problem including combinatory optimization of electrical components, voltage level selection, number of offshore substations (OS) determination as well as cable connection layout design while the other sort is the OS location optimization which is a continuous optimization problem. A combinatory optimization of the offshore wind farm electrical system was presented using a genetic algorithm (GA) in [2] 
with the objective of minimizing overall cost. Similarly, different electrical system topology concerning voltage level, electrical equipment selection and internal cable network design were compared in [3] considering power losses, the reliability of the system and total investment within the objective function. [2][3] contributed to the electrical system of the offshore wind farm by reducing overall investment. However, it can be noticed that the internal cable connection pattern is simply selected from a database, which contains several industrial designs. As one of the main expenses of the electrical system, the cost of cables can be further reduced if the cable connection scheme can be designed optimally. In [4], the collection system (CS) cable connection layout of was optimized using a cluster-based algorithm. Based on the graph theory, the similarity of cable connection layout and minimum spanning tree (MST) formulation was compared in [1][6]. Through greedy algorithm [5], the CS cable connection layout with the minimal cost was found in [1][6]. In addition to that, GA is also widely adopted in optimizing the internal cable connection scheme for offshore wind farm [7][8]. In [7], the CS layout was optimized with multi-objectives: minimizing total cable length, capital investment or power losses. Compared with the scheme found by Prim's algorithm, the proposed method show [7] it's superior in finding a better solution which benefits the objective function. In [8], a larger capacity offshore wind farm with four OS was selected as the case study. The GA was introduced and integrated with the traveling salesman problem (TSP) algorithm [8] to optimize the cable connection schemes in each sub-region associated with one OS. To minimize the expense of submarine cables, [9] proposed an improved GA algorithm which combines immune algorithm to help get an optimized cable connection scheme.

The location of OS plays an important role in internal cable connection pattern design [12]. From the conclusion of [12], it is more economical to build up the OS in the center of an offshore wind farm. Compared with the engineering work [12], an optimization method is introduced in [13] to decide the OS location from several available positions. From [12][13], it can be known that the OS location and the cable connection scheme are two dominant factors in internal cable system scheme design which are interrelated and should be considered in the optimization of the electrical system of offshore wind farm simultaneously.

Besides investment, energy production, which can really generate benefits, is another point that should be considered when designing an offshore wind farm. However, in [5] to [13], the cable connection layout was optimized only by minimizing the total cable cost without considering the power losses. Though power losses were considered in [3] and [4], the wake effect is not included. In previous work [14], a method to calculate the energy yields regarding various wind velocity and direction has already been proposed which is the basis of wake losses estimation in this paper. The main contributions are as follows: 1) The cable connection layout without crossings is ensured based on the sign of cross product, which is a new contribution. 2) For a given wind farm micro-siting, the location of OS, the cable routes and type have been optimized simultaneously. 3) $L C O E$ is used to evaluate the performance of each cable connection scheme which concerns both energy yields and investment. The proposed method is implemented in the Norwegian Centre for Offshore Wind Energy (NORCOWE) reference wind farm and the results show that $1.75 \%$ LCOE reduction can be realized.

This paper is organized into the following. The mathematical models are introduced in section II at first while section III specified the objective function. The proposed optimization procedure is given in section IV. Section V is the case study where the NOCOWE reference offshore wind farm (NRWF) is selected as the benchmark. Section VI summarizes the dominating conclusions.

\section{MATHEMATICAL MODELS}

\section{A. Wake Model}

Presently, Jensen model is widely used to describe the attribute of wind when it encounters the WT blades quantitatively [15]. Based on the momentum conservation, the wake is assumed to be expanded linearly in this model. Then the wind speed in the wake can be expressed as follow [16].

$$
V_{x}=V_{0}-V_{0}\left(1-\sqrt{1-C_{t}}\right)\left(\frac{R_{0}}{R_{0}+k_{d} x}\right)^{2}\left(\frac{S_{e f f}}{S_{0}}\right)
$$

The decay constant, $k_{d}$, is the slope rate of wake expansion. For the offshore environment, the suggested value is 0.04 [22] As described in [15], the wake can be regarded to be expanded linearly and the wake losses estimation of the whole wind farm is based on the 'sum of square' method [16]. Based on the finding in [17], Jensen model shows less prediction error for wake losses estimation. Besides, the Jensen model is widely used in wind farm layout optimization [14], [18]-[21] due to its simplicity in the calculation which results in less computational time as mentioned in [14][19][22].

The energy production of downwind WT could be influenced by the wakes generated by the upwind WTs. Considering the wind velocity and direction's impacts, the energy production program will involve lots of superposition and judgment procedure which makes the calculation process more complex. In [14], an efficient method of wake losses estimation has already been proposed. Based on that, the wind velocity of the WT at $\mathrm{n}^{\text {th }}$ row, $\mathrm{m}^{\text {th }}$ column can be written as:

$$
V_{n, m}=V_{0}-\sqrt{\sum_{i=1}^{N_{\text {row }}} \sum_{j=1}^{N_{c o l}}\left[V_{d e f, i j}\right]^{2}}
$$

\section{B. Loss Calculation}

The power extracted from each WT is calculated by assuming a maximum power point tracking (MPPT) control strategy [23] which is the same model that we used in [14]. The wind speed arrived at the downwind WT was calculated using (2), the power production of this WT will be calculated by interpolating the $C_{p}$ v.s. wind speed lookup table in [24]. Finally, the overall power production can be summarized in the following: 


$$
P_{t o l}=\sum_{m=1}^{N_{c o l}} \sum_{n=1}^{N_{\text {row }}} P_{m, m n}
$$

It is assumed that the operating voltages for all cables are one per unit and then the power losses of cables can be written as:

$$
\begin{gathered}
P_{\text {loss }, \mathrm{i}}=\left(\frac{\sum_{i=1}^{n} P_{i}-\sum_{i=1}^{n-1} P_{\text {loss }, \mathrm{i}}}{\sqrt{3} U_{\mathrm{i}, \text { rated }}}\right)^{2} R_{r e s, \mathrm{i}} \\
R_{\text {res }, i}=\rho_{\text {res }, i} \frac{l_{\text {res }, i}}{S_{\text {res }, i}}
\end{gathered}
$$

The overall power losses of cables are the summation of each cable loss which can be expressed in the following.

$$
P_{\text {tol, loss }}=\sum_{i=1}^{N} P_{\text {loss, } i}
$$

Combining (3) to (6), the energy production reached the onshore substation is expressed in the following:

$$
E_{t o l, a v}=\frac{\sum_{t=1}^{T_{E}}\left(P_{t o l, t}-P_{t o l, l o s s, t}\right) T_{t}}{T_{E} T_{t}}
$$

\section{Cost Model}

In this work, the cost model proposed in [25] is adopted. Then the cost of each cable can be expressed as:

$$
C_{i}=A_{1}+A_{2} \exp \left(\frac{A_{3} \sqrt{3} I_{i, \text { rated }} U_{i, \text { rated }}}{10^{8}}\right)^{2}
$$

The cable's sectional area is decided under the limitation of cable current carrying density. Usually, the sectional area changes from the further WT to the closer one. The further the WT locates, the smaller the cable sectional area is. The maximum current that each cable would undertake will be decided by the selected voltage level as well as the number of WTs that connected after it. Once the maximum current is calculated, the sectional area will be decided according to its current carrying ability which can be found as a lookup table in [38].

\section{Methods FOR CABLE CONNECTION LAYOUT DESIGN}

In this section, the line segments judgment method which is used to ensure the cable connection layout without crossings is introduced at first. After that, a heuristic algorithm, integer particle swarm optimization (IPSO) which is widely used to solve non-linear problems is specified.

\section{A. Spanning Tree}

In graph theory, the concept of a tree is a connected graph with no circuit while the spanning tree is regarded as a tree which connects all vertices [26]. For the offshore wind farm case, a configuration without crossings is desirable since lower investment can be realized. Hence, the cable connection layout problem can be described mathematically as finding a spanning tree layout without crossings for an offshore wind farm with minimum $L C O E$.

\section{B. The judgment of Line Segments Intersection}

The classic method to determine whether two line segments intersect is to check whether each segment straddles the line containing the other or not [27]. The realization of this line segment judgment method is based on the concept of the cross product. The general idea can be explained using a simple example as illustrated in Fig. 1
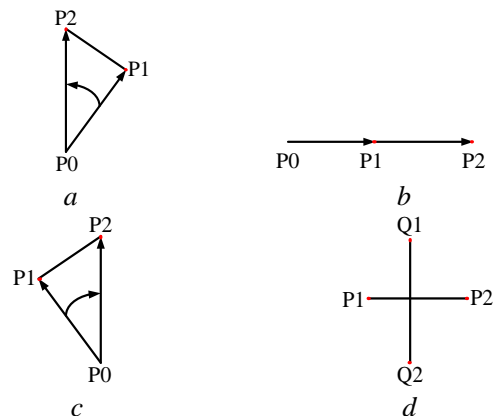

Fig. 1. The illustration of the cross product. (a) P0P2 obtained by moving P0P1 anti-clockwise. (b) P0, P2 and P1 are in a line. (c) P0P2 obtained by moving P0P1 clockwise. (d) P1P2 and Q1Q2 are intersected.

Assume there are two line segments P1P2 and Q1Q2 which are required to be judged. The red dots in Fig. 2 show the endpoints of these line segments. To determine whether each segment straddles the other, in other words, whether they are intersected, the cross product can be used as is shown with a simple example as Fig. 2 (a) to (c).

Fig. 1 (a) shows that if $(\mathrm{P} 2-\mathrm{P} 0) \times(\mathrm{P} 1-\mathrm{P} 0)<0$, then $\mathrm{P} 2 \mathrm{P} 0$ can be obtained by rotating P1P0 anti-clockwise. (b) shows that if $(\mathrm{P} 2-\mathrm{P} 0) \times(\mathrm{P} 1-\mathrm{P} 0)=0$, then $\mathrm{P} 1, \mathrm{P} 2$, and $\mathrm{P} 0$ are on the same line. (c) shows that if $(\mathrm{P} 2-\mathrm{P} 0) \times(\mathrm{P} 1-\mathrm{P} 0)>0$, then $\mathrm{P} 2 \mathrm{P} 0$ can be obtained by rotating $\mathrm{P} 1 \mathrm{P} 0$ clockwise. By using this method, it can be easily known whether two points (P2 and P1 or Q2 and $\mathrm{Q} 1)$ are on the same side of one segment (P1P2 or Q1Q2).

Based on the theory mentioned above, the intersection judgment of two line segments can be determined as follow:

$$
\left\{\begin{array}{c}
\left(P_{1}-Q_{1}\right) \times\left(Q_{2}-Q_{1}\right)\left(Q_{2}-Q_{1}\right) \times\left(P_{2}-Q_{1}\right)>=0 \\
\left(Q_{1}-P_{1}\right) \times\left(P_{2}-P_{1}\right)\left(P_{2}-P_{1}\right) \times\left(Q_{2}-P_{1}\right)>=0
\end{array}\right.
$$

where $\times$ is the symbol of the cross product.

Simply speaking, if the two endpoints of one line segment are not on the same side of the other line segment, then the two lines are intersected as shown in Fig. 1 (d). The cable connection layout without crossings obtained in this paper is based on this method.

\section{IPSO}

Stochastic optimization method, for instance, GA and PSO show good performance in solving a non-convex problem [28]. 
Initially, GA is proposed for solving integer optimization problems while PSO aims at solving discrete optimization problems. In order to increase the adaptation of these algorithms, some modified versions have been proposed which can cope with integer or mixed-integer optimization problems. In this work, the IPSO is chosen to solve the problem since it requires less computation time compared with GA [29]. The mathematical expression is as follows:

$$
\begin{gathered}
v_{i}^{k+1}=\operatorname{int}\left[w v_{i}^{k}+l_{1} r_{l}\left(l c_{i}^{k}-x_{i}^{k}\right)+l_{2} r_{2}\left(g l^{k}-x_{i}^{k}\right)\right] \\
x_{i}^{k+1}=x_{i}^{k}+v_{i}^{k+1}
\end{gathered}
$$

In PSO, inertia weight, $w$, is a control parameter which can provide a balance between global and local explorations. In order to reduce the sensitivity of the final solution to inertia weight, an adaptive parameter control strategy is selected in this work. The detailed explanation of adaptive PSO (APSO) is specified in [30].

\section{MATHEMATICAL FORMULATION OF THE PROBLEM}

In this section, the mathematical model of the problem is constructed at first. After that, the optimization is presented and explained in detail.

\section{A. Heuristic Method for Cable Connection Layout Design}

In an offshore wind farm, there could be hundreds of WTs. If the WT and OSs are imagined as vertices, then the number of spanning trees of this graph will be huge and it is impossible for a computer to exhaust all the solutions to find the optimal one. In order to solve the above problem, a heuristic method is proposed in this paper. This proposed method is explained with a simple instance which is shown in Fig. 2.

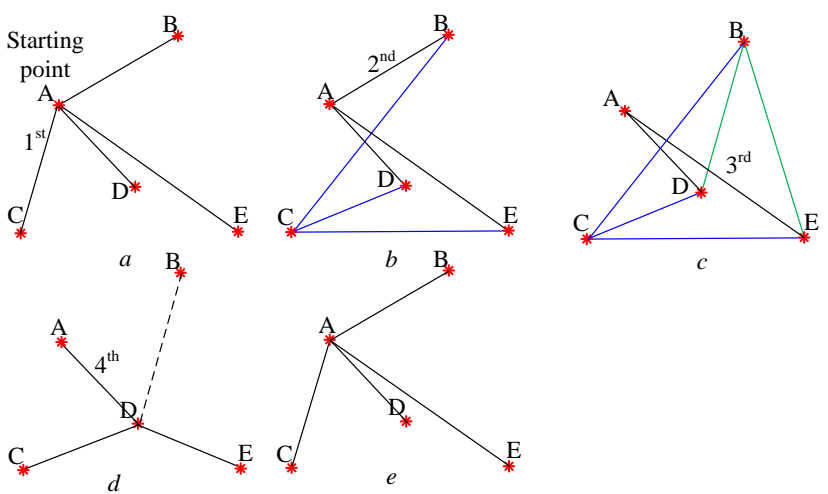

Fig. 2. Illustration of the proposed method. (a) - (d) are respectively the first, second, third and last steps when generating a spanning tree for a graph with 5 vertices. (e) the final layout.

For this heuristic method, the layout is stochastically given at the beginning by stating the branch numbers in every layout formulation process. A simple example is made here to make the layout formulation process understandable. In this example, the final layout as shown in Fig. 2 (e) is given at the beginning stochastically. It is assumed that five vertices (A to E) represented by red stars are to be connected which means 4 decisions (the number of decisions equals the total number of vertices in the graph minus one) have to be made. The number alongside the line shows the order of decision making and the nearest branch to this number is the selected branch in this decision making step. Point $\mathrm{A}$ is assumed to be the starting point for the search (in the simulation, the starting point is always the OS). Fig. 2 (a) to (d) illustrated the feasible solutions in each decision making step. It can be seen in Fig. 2 . (a) that the possible branches that can be chosen in this step are illustrated with a black line. For a 5-vertex graph, there are $4 * 1=4$ options at the first step of the spanning tree formulation process; it is assumed that branch AC is selected in this step. (b) shows the possible branches that can be chosen in second decision making the step. Since vertices A and C has already included in the present tree layout, two starting points (A and C) can be selected. Since AC is already in the formulated tree layout, it cannot be regarded as the potential solution anymore. The possible branches that can be selected associated with A and $\mathrm{C}$ are illustrated with black and blue lines respectively. It can be seen that there are $3 * 2=6$ options which can be chosen in this step. As illustrated in Fig. 2. (b), branch AB is selected in this step. After this step, only 2 points (D and E) are left and required to be connected. By following the same procedure, (c) uses black (started from A), blue (started from C) and green lines (started from B) to illustrate all the possible branches that can be selected. (d) shows the last step and there are $1 * 4=4$ options, that is, DA, DC, DE and DB in this case. One thing that should be noticed that line DD (indicated with dotted line) intersects $\mathrm{AE}$ which is already in the formulated tree. Hence, if this line is selected, then the penalty function which will be introduced in section IV.C will be applied. When the entire vertex is included in the formulated tree layout, then the layout formulation process completes.

From the above example, it can be concluded as follows: the complete graph on $\mathrm{N}$ vertices has $(\mathrm{N}-1)$ ! spanning trees. Since the number of self-intersecting spanning trees varies with the positions of vertices, it is hard to conclude how many spanning trees of a graph that do not self-intersect there are. Hence, there are two problems that should be solved with the proposed method. One is to reduce the computational cost for the computer (the complexity of this problem is $\mathrm{O}\left(\mathrm{n} !^{\wedge} 2\right)$ which means that it is an NP-hard problem [31]). Even though these intersecting spanning trees can reduce the number of potential solutions, the problem could still be NP-hard), the other is to eliminate every spanning tree with intersecting line segments but these depend on the specific layout and are impractical to enumerate.

\section{B. Objective Function}

The target of this work is to minimize the $L C O E$ of the offshore wind farm. As mentioned in [32], the $L C O E$ includes two aspects: discounted investment and energy yields. In this work, only discounted cable investment is considered. Based on the model presented in section II. C, the overall cable investment can be expressed as follows:

$$
C_{a l}=\sum_{i}^{N} C_{i}\left(x_{i}\right) H_{i}\left(x_{i}\right) Q_{i}\left(x_{i}\right)
$$

As can be seen from (12), the cable cost is decided by the selected spanning tree (cable connection layout) as introduced in section IV. A and this spanning tree is formulated by the decided optimization variable, $x_{i}$. 
Then the objective function can be expressed as:

$$
\min \left(L C O E=\frac{C_{a l} r r(1+r r)^{N_{l i f e}}}{\left[(1+r r)^{N_{l i f e}}-1\right] E_{t o l, a v}}\right)
$$

S.t.

$$
1 \leq x_{i} \leq N_{w}
$$

\section{Penalty Function}

As introduced in section III. B and III. C, the layout formulation problem can be solved using knowledge of computational geometry [33] while PSO algorithm has good performance in solving the unconstrained optimization problem when the problem is NP-hard. However, if the spanning trees with intersecting line segments are merely deleted from the simulation, the particles will not have explicit directions to move in. As a result, there is a high possibility that a local optimal solution will be found by PSO. To tackle this problem, a penalty function is adopted which can be written as follows:

$$
\phi(\mathrm{Q})=I_{N}
$$

If one set of crossed lines is found then the penalty function will be triggered and thus the objective function will be penalized by adding additional cost. Considering the penalty function, the objective function should be rewritten in the following:

$$
\min (L C O E)=\min \left[\frac{\left(C_{a l}+I_{N} P F\right) r r(1+r r)^{N_{\text {life }}}}{(1+r r)^{N_{\text {life }}}-1} \frac{1}{E_{\text {tol }, a v}}\right]
$$

\section{Assumptions and Constraints}

Some assumptions and constraints are made in this project which is described in the following.

- The voltage levels for the CS and the transmission system (TS) are assumed to be $66 \mathrm{kV}$ and $220 \mathrm{kV}$ respectively.

- Yaw misalignment [34] that is the phenomenon that the rotating speed of yaw cannot follow the speed changing of wind direction; as a result, the nacelle will not be able to face to the wind flowing direction all the time. In this project, the yaw misalignment is not considered when calculating the energy yields of the wind farm.

- To simplify the power losses calculation, all cables are assumed to be operated in 1 p.u. which neglects the voltage regulation constraint. This assumption is made since in one of our previous works [35] we found that the voltage deviation within offshore wind farm is very small (around 1\%).

- The impacts of reactive power for power losses are neglected.

- The seabed structure's impact on the cable length is neglected which means that the cable length is calculated by using the geographic distance between the corresponding WTs.

- The reliability related impacts on energy yield are neglected

\section{E. Optimization Framework}

In this work, the optimized cable connection scheme is found by the proposed method. The optimization process to reach the optimized scheme by proposed method can be seen in Fig. 3.

Climatological Information: The time series wind farm should be disposed of statistically before it can be used for energy production calculation for a whole wind farm. Based on the measured wind speed, the wind rose is generated statistically in this work. The detailed information for the wind rose and how to use it for wake losses evaluation is specified in a previous work [14].

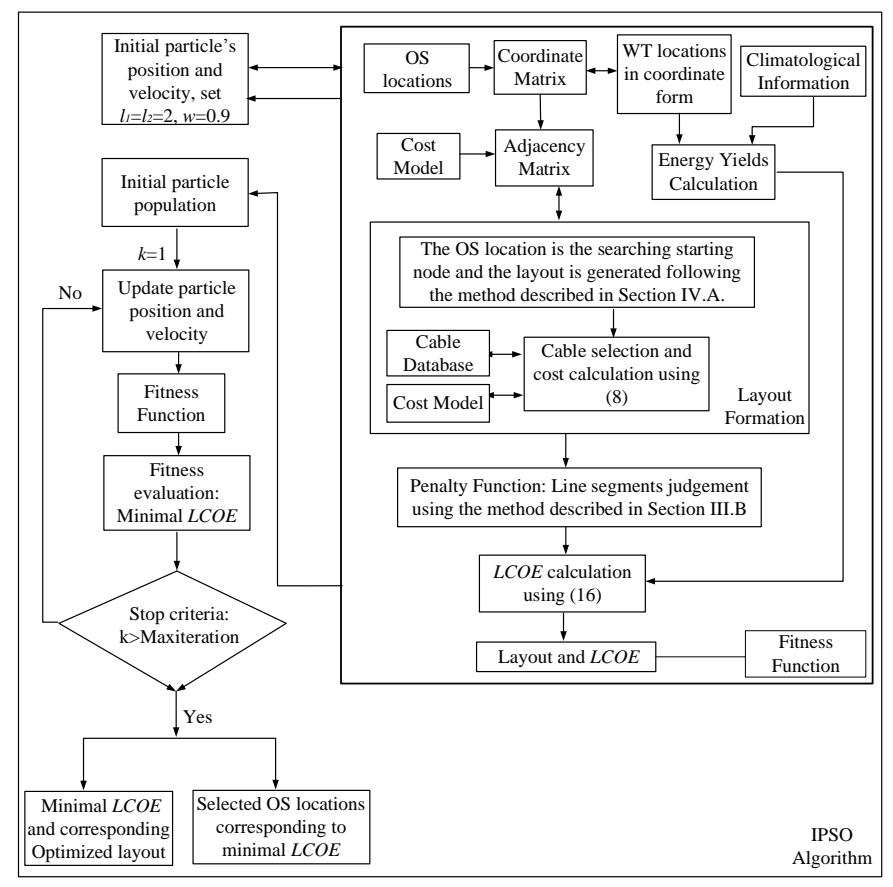

Fig. 3. The optimization framework for the proposed method.

In the beginning, the particles' location includes twofold information: one is a series of randomly selected branches at each step as described above, the other is two randomly given OS location sequence numbers from the given available positions. The particles will be delivered to the Fitness Function and be utilized to create the coordinate matrix. Based on the cost model and coordination matrix, the adjacency matrix will be formed. The energy yields of each WT can be calculated based on the coordinate matrix as well as the Climatological Information [36]. The cable connection scheme will be generated in the Layout Formation using the method presented in section IV. A. After that, the scheme will be checked in the penalty function and then the LCOE will be obtained using (16). The optimized layout with corresponding $L C O E$ value is regarded as the initial particle population and it is also the basis for updating the particle position later.

It should also be noticed that the particles containing the information of the selected branch sequence number at each step as well as the OS location would be renewed and delivered to the Fitness Function one by one. By obeying the same process as in the first calculation, the obtained cable connection scheme with homologous $L C O E$ will be transferred to the 
Fitness Evaluation for comparison. The optimization process can also terminate when a maximum number of iterations is reached. At last, a series of branch sequence numbers and the selected locations for OSs which is with the lowest LCOE will be chosen. The optimized layout is formulated according to the selected branch number in each step during the layout formulation process.

\section{Case Study}

The NEWF is introduced at first. Then the simulation results and discussion will be given. The WT locations are fixed and the optimization is done by choosing the best location to install offshore substation and the corresponding cable connection layout. Several trials have been done in IPSO and the best solution among all trials will be selected as the final result.

\section{A. NRWF}

The NRWF [37] is assumed to be located $80 \mathrm{~km}$ west of the German island of Sylt. The installed capacity of the wind farm is $800 \mathrm{MW}$. The geographical distance between OS and onshore substation is $80 \mathrm{~km}$. The illustration of WT positions is shown in Fig. 4.

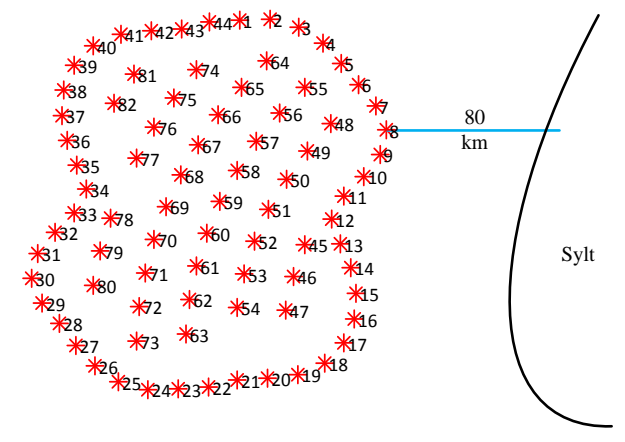

Fig. 4. The WT positions' illustration for NRWF.

In Fig. 4, the red stars represent the WTs and the number alongside each WT is the sequence number. There are 82 positions in total which can be used to install WT or establish OS. In the NRWF layout, the OS locations have been selected and the cable connection layout is shown in Fig. 5.

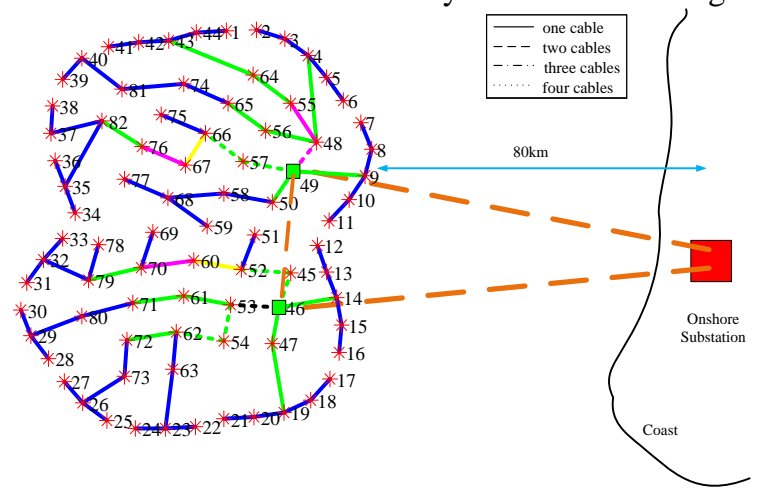

Fig. 5. NRWF Cable Connection Scheme.

In Fig. 5, the two OSs are assumed to be located in positions No. 46 and 49 respectively. The green squares are
OSs. The lines represent the cable connection scheme while the line colors show the ratings of the cables as listed in Table 1. The number of cables between some pairs of WTs is illustrated with different types of lines. The current ratings for different types of cables are listed in Table 2 [38].

TABLE I. SPECIFICATION OF CABLES COLOR

\begin{tabular}{|c|c|c|c|c|c|c|}
\hline & \multicolumn{5}{|c|}{ CS } & TS \\
\hline Color & blue & green & purple & yellow & black & brown \\
\hline $\begin{array}{c}\text { Sectional Area } \\
(\mathrm{m} \mathrm{m} 2)\end{array}$ & $\begin{array}{c}95 / \\
150\end{array}$ & $240 / 300$ & $400 / 500$ & $630 / 800$ & 1000 & 300 \\
\hline
\end{tabular}

The NRWF is composed of 80,10 MW DTU WT. The detailed specification of this WT is concluded in Table 3. The time series wind speed is drawn as a wind rose which is illustrated in Fig. 6.

TABLE II. DTU 10MW WIND TURBINE SPECIFICATION [39]

\begin{tabular}{|c|c|}
\hline Parameter & $10 \mathrm{MW}$ DTU Wind Turbine \\
\hline Cut-in Wind Speed & $4 \mathrm{~m} / \mathrm{s}$ \\
\hline Rated Wind Speed & $11.4 \mathrm{~m} / \mathrm{s}$ \\
\hline Cut-out Wind Speed & $25 \mathrm{~m} / \mathrm{s}$ \\
\hline Rotor Diameter & $178.3 \mathrm{~m}$ \\
\hline Rated Power & $10 \mathrm{MW}$ \\
\hline & \\
& \\
&
\end{tabular}

Fig. 6. Wind rose generated based on the measured data near FINO3.

\section{B. Scenario I: Optimized Scheme with Given OS Positions}

In this scenario, the cable connection scheme is optimized by assuming that No. 46 and 49 are the OSs which transmits power to the onshore substation. The optimized layout using the proposed method is shown in Fig. 7.

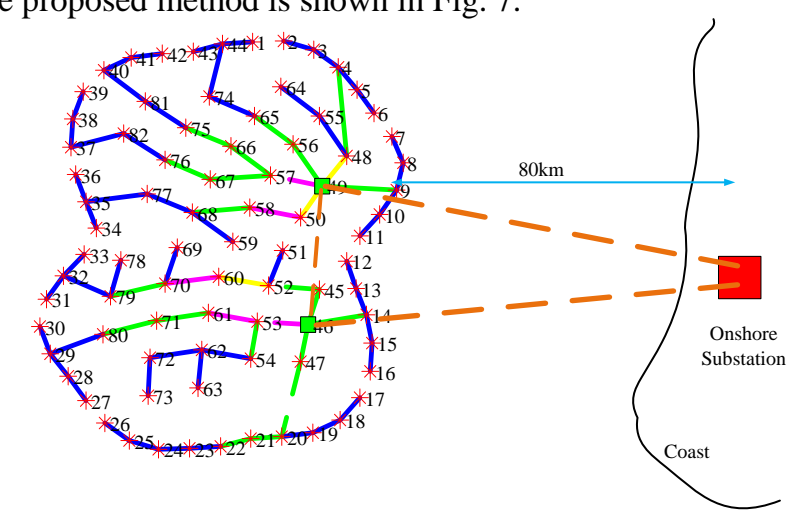

Fig. 7. The optimized cable connection scheme for the scenario I. 
TABLE III. CURRENT RATING FOR SubMarine CABles [38]

\begin{tabular}{|c|c|c|c|c|c|}
\hline \multicolumn{4}{|c|}{$66 \mathrm{kV}$ cable } & \multicolumn{2}{|c|}{$220 \mathrm{kV}$ cable } \\
\hline Cross section $(\mathrm{mm} 2)$ & Current rating $(\mathrm{A})$ & Cross section (mm2) & Current rating $(\mathrm{A})$ & Cross section (mm2) & Current rating $(\mathrm{A})$ \\
\hline 95 & 300 & 400 & 590 & 300 & 530 \\
\hline 120 & 340 & 500 & 655 & 400 & 590 \\
\hline 150 & 375 & 630 & 715 & 500 & 655 \\
\hline 185 & 420 & 800 & 775 & 630 & 715 \\
\hline 240 & 480 & 1000 & 825 & 800 & 775 \\
\hline 300 & 530 & & & 1000 & 825 \\
\hline
\end{tabular}

\section{Scenario II: Optimized Cable Connection Scheme and OS Positions}

In this scenario, the positions of the OSs are optimized together with the cable connection scheme. The two OS positions should be selected from the predefined 82 positions and the other positions will be used to install WTs. The cable details regarding voltage level as well as a sectional area for transmission lines are the same as in the NRWF. The optimized cable connection layout using IPSO is shown in Fig. 8.

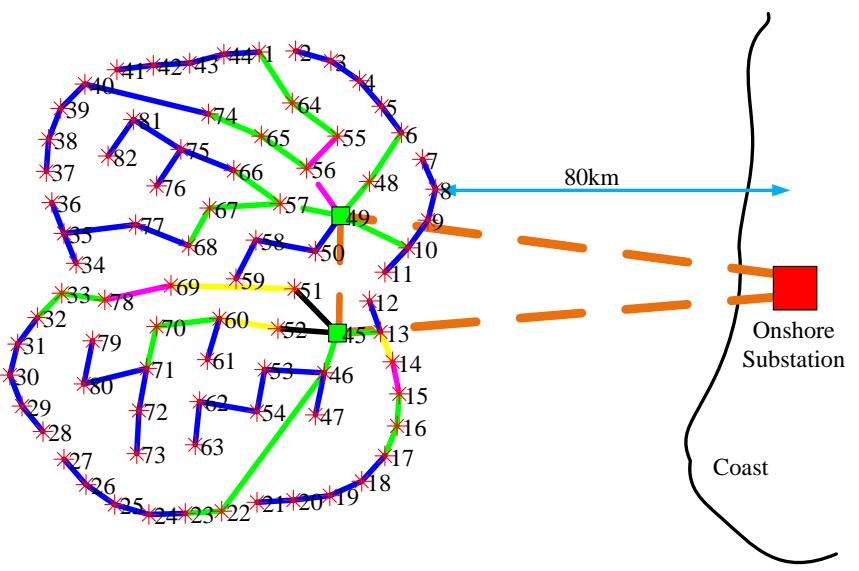

Fig. 8. The optimized cable connection scheme for scenario II.

As shown in Fig. 8, positions No. 49 and 45 are selected to construct the OSs instead of 49 and 46 in this scenario.

\section{Results and discussion}

Table 4 concludes the economic information of three different cable connection schemes including scenario I, II and the NRWF layout.

As listed in Table 4, the cost of connecting cables means the cable used to connect OSs. The optimized layouts in the scenario I and II can reduce the LCOE by $1.02 \%$ and $1.75 \%$ respectively compared with the NRWF layout. By taking the
OS locations into the optimization, the optimized layout in scenario II can further reduce the LCOE by $0.74 \%$ compared with scenario I. The best layout in this simulation is scenario II, which can reduce the energy losses and cable cost by $0.53 \%$ and $1.73 \%$ respectively compared with the NRWF layout while the energy reached PCC can be increased only by $0.02 \%$.

Hence, the dominant factor in the reduction of LCOE is the cable cost. It should also be noticed that the achieved reduction in the simulation only concerns the expenses on the cables. If more costs such as WT investment, installation and O\&M costs, etc are taken into account, then realized results should be even smaller. However, considering the high price of submarine cables, only a small percentage of reduction will introduce a large amount of investment savings.

\section{Conclusion}

To lower the $L C O E$ of the offshore wind farm, the cable connection scheme is expected to be carefully designed. In this paper, the proposed algorithm can guarantee a cable connection scheme without crossings which is desirable for offshore wind farm planning. The simultaneous optimization of cable connection scheme, cable section area, and OS positions contributes to an optimized cable connection layout which represents the best tradeoff between the required investment and power transmitted to an onshore substation. The LCOE index which is commonly used in wind farm micro-siting optimization is adopted in this paper to give a comprehensive analysis of the cable connection scheme performance. Simulation results reveal that the designed layout using proposed method outperformed than the NRWF layout in reducing $L C O E$ by $1.75 \%$. It demonstrates the effectiveness of the proposed method for cable connection layout design.

\section{ACKNOWLEDGMENT}

The authors would like to thank the Norwegian Centre for Offshore Wind Energy (NORCOWE) under grant 193821/S60 from the Research Council of Norway (RCN).

TABLE IV. SPECIFICATION OF OPTIMIZED CABLE CONNECTION LAYOUT

\begin{tabular}{|c|c|c|c|c|c|c|c|}
\hline & $\begin{array}{c}\text { Energy yield } \\
(\mathrm{GWh})\end{array}$ & $\begin{array}{c}\text { Energy losses } \\
\text { (GWh) }\end{array}$ & $\begin{array}{c}\text { Energy yields at } \\
\text { PCC (GWh) }\end{array}$ & $\begin{array}{l}\text { Cost of collection } \\
\text { cables (MDkk) }\end{array}$ & $\begin{array}{c}\text { Cost of transmission } \\
\text { cables (MDkk) }\end{array}$ & $\begin{array}{c}\text { Total Cost of } \\
\text { cables (MDkk) } \\
\end{array}$ & $\begin{array}{c}\mathrm{LCOE} \\
(\mathrm{DKK} / \mathrm{MWh}) \\
\end{array}$ \\
\hline NRWF & 4015.17 & 87.5 & 3927.67 & 229.25 & 1187.93 & 1417.18 & 360.92 \\
\hline Scenario I & 4015.17 & 87.01 & 3928.16 & 214.93 & 1187.93 & 1402.86 & 357.24 \\
\hline Scenario II & 4015.67 & 87.04 & 3928.63 & 215.24 & 1177.40 & 1392.64 & 354.59 \\
\hline
\end{tabular}

\section{REFERENCES}

[1] Ling-Ling, H., Ning, C., Hongyue, Z., Yang, F., "Optimization of largescale offshore wind farm electrical collection systems based on
[2] Zhao, M., Chen, Z., Blaabjerg, F., "Application of genetic algorithm in electrical system optimization for offshore wind farms," Int. Conf. on Electric Utility Deregulation and Restructuring and Power Technologies (DRPT), 2008. 
[3] Bahirat, H. J., Mork, B. A., Hoidalen, H. K., "Comparison of wind farm topologies for offshore applications," 2012 IEEE Power and Energy Society General Meeting, 2012, pp. 1-8.

[4] Dutta, S., Overbye, T.J., "A clustering based wind farm collector system cable layout design," 2011 IEEE Power and Energy Conference at Illinois (PECI), 2011, pp. 1-6.

[5] Devore, R. A., Temlyakov, V. N., "Some remarks on greedy algorithm," Adv. Comp. Math., 1996, pp. 173-187.

[6] Dutta, S., Overbye, T. J., "Optimal Wind Farm Collector System Topology Design Considering Total Trenching Length," in IEEE Trans. Sustainable Energy, 2012 (3), pp. 339-348.

[7] Jenkins, A.M., Scutariu, M., Smith, K.S., "Offshore wind farm interarray cable layout,” PowerTech (POWERTECH), 2013 IEEE Grenoble, 2013, pp. 1-6.

[8] Gonzalez-Longatt, F. M., Wall, P., Regulski, P., Terzija, V. "Optimal electric network design for a large offshore wind farm based on a modified genetic algorithm approach,” IEEE Syst. J., vol. 6, no. 1, pp. 164-172, Mar. 2012.

[9] Li, D. D., He, C., Fu, Y., "Optimization of internal electric connection system of large offshore wind farm with hybrid genetic and immune algorithm," in Proc. 3rd Int. Conf. Electr. Utility DRPT, 2008, pp. 24762481.

[10] Funke, S. W., Farrell, P. E., Piggott, M. D., "Tidal turbine array optimisation using the adjoint approach," Renewable Energy, 2014 (63), pp. 658-673.

[11] Culley, D. M., Funke, S. W., Kramer, S. C., Piggott, "Integration of cost modelling within the micro-siting design optimisation of tidal turbine arrays," Renewable Energy, 2016 (85), pp. 215-227.

[12] Hopewell, P. D., Castro-Sayas, F., Bailey, D. I., "Optimising the Design of Offshore Wind Farm Collection Networks," UPEC '06. Proceedings of the 4-1st International Universities Power Engineering Conference, 2006 (1), pp. 84-88

[13] Lumbreras, S., Ramos, A., "Optimal Design of the Electrical Layout of an Offshore Wind Farm Applying Decomposition Strategies", Power Systems, IEEE Transactions on, 2013 (28), pp. 1434 - 1441.

[14] Hou, P., Hu, W., Soltani, M., Chen, Z., “Optimized Placement of Wind Turbines in Large Scale Offshore Wind Farm using Particle Swarm Optimization Algorithm," IEEE Transactions on Sustainable Energy, 2015 (6), pp.1272-1282.

[15] González-Longatt, F., Wall, P., Terzija, V. "Wake effect in wind farm performance: Steady-state and dynamic behavior," Renewable Energy, 2011 (39), pp. 329-338, Sep. 2011

[16] WindPRO/PARK, "Introduction wind Turbine Wake Modelling and Wake Generated Turbulence,” EMD International A/S, Niels Jernes Vej 10, DK-9220 Aalborg, Denmark, 1 Apr. 2005.

[17] V. DR, "Investigation of observed and modelled wake effects at Horns Rev using windpro," Report, Technical University of Denmark, MEK Department, Fluid Mechanics Section, Denmark 2006.

[18] Pérez, B., Mínguez, R., Guanche, R. "Offshore wind farm layout optimization using mathematical programming techniques," Renewable Energy, 2013 (53), pp. 389-399.

[19] Guirguis, D., Romero, D. A., Amon, C. H. "Toward efficient optimization of wind farm layouts: Utilizing exact gradient information," Applied Energy, 2016 (179), pp. 110-123.

[20] Gu, H., Wang, J., "Irregular-shape wind farm micro-siting optimization,” Energy, 2013 (57), pp. 535-544.

[21] Pookpunt, S., Ongsakul, W., "Optimal placement of wind turbines within wind farm using binary particle swarm optimization with time- varying acceleration coefficients," Renewable Energy, 2013 (55), pp 266-276.

[22] Beaucage, P., Brower, M., Robinson, N., Alonge, C., "Overview of six commercial and research wake models for large offshore wind farms,' Proceedings EWEA 2012, 2012, pp. 95-99.

[23] Qiao, W., "Intelligent mechanical sensorless MPPT control for wind energy systems," Power and Energy Society General Meeting 2012, 2012, pp. 1-8.

[24] Bak, C., Zahle, F., Bitsche, R., Kim, T., Yde, A., Henriksen, L.C., Natarajan, A., Hansen, M. H., "Description of the DTU 10 MW Reference Wind Turbine," DTU Wind Energy, 2013.

[25] Lundberg, S., "Performance comparison of wind park configurations," Department of Electric Power Engineering, Chalmers University of Technology, Department of Electric Power Engineering, Goteborg, Sweden, Tech. Rep. 30R, Aug. 2003.

[26] Bondy, J. A., Murty, U. S. R., "Graph theory with applications," the Macmilllan Press Ltd., 1976.

[27] Cormen, T. H., Leiserson, C. E., Rivest, R. L., Stein, C., "Introduction to algorithms," third edition, MIT Press, $2001-1180$.

[28] Zhang, P. Y., "Topics in wind farm layout optimization: Analytica wake models, noise propagation, and energy production," master thesis, University of Toronto, 17 Jul. 2013.

[29] Hassan, R., Cohanim, B., Weck, O. de, "A comparison of particle swarm optimization and the genetic algorithm," in Proceedings of the 46th AIAA/ASME/ASCE/AHS/ASC structures, structural dynamics and materials conference, 2005.

[30] Z.-H. Zhan, J. Zhang, Y. Li, and H. S.-H. Chung, "Adaptive particle swarm optimization,” IEEE Trans. Syst., Man, Cybern. B, Cybern., 2009 (39), pp. 1362-1381.

[31] Eric W. Weisstein, "NP-Hard Problem," From MathWorld-A Wolfram Web Resource. http://mathworld.wolfram.com/NP-Problem.html.

[32] Zhao, M., "Optimization of Electrical System for Offshore Wind Farms via a Genetic Algorithm Approach," Dissertation submitted to the Faculty of Engineering, Science and Medicine at Aalborg University, Denmark, Oct. 2006.

[33] Coello, C. A., "Theoretical and numerical constraint-handling techniques used with evolutionary algorithms: a survey of the state of the art," Computer Methods in Applied Mechanics and Engineering, 191(11-12), 2002, pp. 1245-1287.

[34] Choi, J., Shan, M., "Advancement of Jensen (Park) wake model," EWEA Conference, Wien, pp. 1-8, Feb. 2013.

[35] Zhang, B., Hou, P., Hu, W., Soltani, M., Chen, C., Chen, Z., "A Reactive Power Dispatch Strategy with Loss Minimization for a DFIG Based Wind Farm," IEEE Trans. on Sustainable Energy, 2016 (7), pp. 914-923.

[36] B. R. Furevik, H. Haakenstad, "Near-surface marine wind profiles from rawinsonde and NORA10 hindcast," Jounal of Geophysical Research, 2012 (117)

[37] "Norcowe annual report 2015," Norwegian Centre for Offshore Wind Energy (NORCOWE), 2015

[38] XLPE Submarine Cable Systems Attachment to XLPE Land Cable Systems-User's Guide. Fredericia, Denmark: ABB Corporation, 2013.

[39] C. Bak et al., "Description of the DTU 10 MW reference wind turbine," DTU Wind Energy, Fredericia, Denmark, Jul. 2013. 